\title{
Primary Neuroendocrine Carcinoma of The Breast
}

\author{
Havva Y. CINKIR, Umut DEMIRCI, Kaan HELVACI, Oznur BAL, Ayse DEMIRCI, \\ Necati ALKIS, Berna OKSUZOGLU
}

Dr. A.Y. Ankara Oncology Training and Research Hospital, Department of Medical Oncology, Ankara, TURKEY

\section{Dear To Editor,}

Neuroendocrine tumors (NET) originate from neuroendocrine cells that are present throughout the body. Most of these cells are located in the gastrointestinal and bronchopulmonary system. Neuroendocrine tumor, is defined by the diffuse expression of neuroendocrine markers, such as chromogranin-A ( $\mathrm{CgA})$, neuron-specific enolase (NSE), synaptophysin and CD56 in more than $50 \%$ of the cell population. ${ }^{1}$ In 1977, Cubilla and Woodruff first reported a carcinoid tumor of the breast. ${ }^{2}$ Recently, primary NET of the breast (BNET) was recognized as a distinct entity, comprising of approximately less than $1 \%$ of all breast cancers. In this rare tumors, treatment modality have not been established. Herein, we reported two cases with early BNET with different management strategies.

A 75-year woman presented with a mass in her left breast. She had hypertension. Mammography and ultrasonography revealed a 20x15 mm lump at the lower outer quadrant. The tumor markers were normal. A biopsy specimen of the mass revealed neuroendocrine carcinoma (NEC), small cell variant. Histological examination of the tumor consisted of atypical cells with round, hyperchromatic nuclei and narrow cytoplasm (Figure 1). Four to five mitotic figures per 10 high power field were counted. There was a widespread lymphovascular emboli. Immunohistochemical study of NSE, synaptophysin, CD57, E-cadherin staining was positive. CgA was focal positivite. Estrogen receptor (ER) was $90 \%$ positive, progesterone receptor (PR) was $80 \%$ positive, cerb B2 score was 0 and the Ki67 proliferation index was 5\%. CD56, CD 31, CK5 / 6, HMWCK, p63, CK 7, CK 20 was negative. To exclude nonmammary primary site, we examined head and neck, torax, abdomen, pelvis and bone marrow however found no abnormalities. Then the patient underwent left breast conserving surgery and sentinel lymph node sampling. In the resected specimen and lymph node, no residual tumor was seen. Patient was diagnosed as breast NEC and received 4 cycles of cisplatin-etoposide chemoterapy. And then radiotherapy was performed. There was no signs of recurrence 30 months after the radiotherapy. A 77-year old women presented with pain and lump in her left breast. Mammography and ultrasonography revealed a lesion of $18 \mathrm{~mm}$ in size with irregular contours at the upper outer quadrant of the left breast. The trucut biopsy was reported as invasive breast carcinoma, grade 2. Left modified radical mastectomy and axillary lymph node dissection was performed. Tumor size was $23 \mathrm{~mm}$. In immunohistochemical study, synaptophysin and $\mathrm{CgA}$ were diffusely positive; ER $80 \%$ positive, PR 90\% positive, cerb B2 score 0 and the Ki67 proliferation index was 10\%. Serum CgA levels: $198 \mathrm{ng} / \mathrm{ml}$ (normal: <94). In systemic tumor screening, there was no tumor focus. She had medical history of hypertension, diabetes mellitus, dyslipidemia, and chronic kidney disease. She had a family history of breast cancer in her daughter. Aromatase inhibitor was started and for about 9 months, she had no tumor reccurence. 


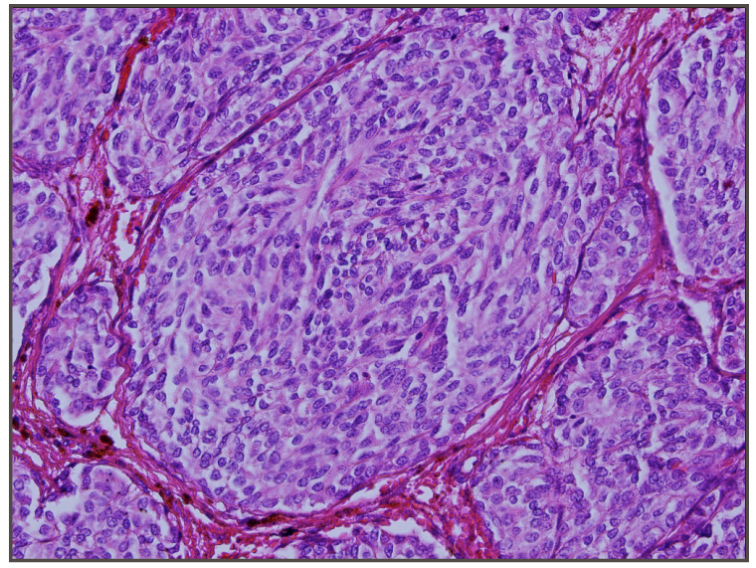

Figure1. Histological findings of tumor: Atypical cells with round, hyperchromatic nuclei and narrow cytoplasm

Although some invasive ductal carcinomas of the breast show areas of neuroendocrine differentiation, primary neuroendocrine carcinoma of the breast is a rare entity. ${ }^{3}$ Tumor incidence rate is low. But, Brask at al found $5.4 \%$ incidence in a pilot study of a Danish population of 240 breast cancer patients. ${ }^{4}$ The reported median age varies from 40 to 70 years, with a higher incidence in women greater than 60 years. ${ }^{5,6} \mathrm{In}$ our two cases, the patients were older than 70 years. Rarely, this tumor be seen younger ages. In literature, Ouzreaih et all reported a youngest women, 22-yearold young woman with BNET. ${ }^{6}$ The histogenesis is still unclear. In the breast, neuroendocrine cells and benign or premalignant neuroendocrine lesions have never been determined. NET is defined by the diffuse expression of neuroendocrine markers. Unfourtunately, neuroendocrine markers are usually not routinely stained, so some cases are overlooked. It is wise to stain them when solid, alveolar, or nested pattern of growth is prominent. ${ }^{3}$ Different classifications, according to the morphological features of histopathology, have been proposed for BNET. In 2012, WHO divided carcinomas with neuroendocrine features into three categories: NET, well-differentiated; NEC, poorly differentiated/small cell carcinoma; and invasive breast carcinoma with neuroendocrine differentiation. ${ }^{3}$ Differential diagnosis of NET of the breast from metastatic tumor is essential because of the differences in treatment approach. Metastatic NET of the breast are more common than BNET. Primary BNET can be diagnosed if the presence of a non-mammary primary site can be clinically ruled out or if an in situ component is histologically detected, or both. ${ }^{6}$ And BNET have no specific clinical or imaging features. Endocrine hormon-related syndromes are extremely rare. ${ }^{6}$ The prognosis for this rare tumor remains controversial. Tumor size, stage of disease at the time of diagnosis, expression of the ER and PR, grade and Ki67 index are important determinants of the prognosis. ${ }^{6}$ Tian et all reported in their study that routine evaluation of Ki67 proliferation index in these unusual tumors may provide more valuable information than mitotic count alone. ${ }^{7} \mathrm{Sa}-$ pino et al suggested that ER and PR expression correlates with favorable prognosis. ${ }^{8}$ Hormone receptor expression is less frequent in the small cell carcinoma type. Her2 expression is nonexistent or very rarely present in BNET like. Francesca et all reported that tumor gene profil showed luminal A molecular type in their study. Because of this, their patients had good prognosis. ${ }^{9}$ In our two cases, although second case had small cell type, tumors were strongly stained with hormon receptor. Consistent with the literature, her2 expression was not detected.Histologic grade is important predictor of prognosis. Solid NET and atypical carcinoids are considered to be well-differentiated tumours. However, small cell or oat cell carcinoma and large cell neuroendocrine carcinoma are poorly differentiated. In general, the treatment reported in the literature for BNET is similar to the treatment for the invaziv ductal carcinoma. The treatment approach may include surgery and radio--therapy depending on tumor size and the lymph node status. However the adjuvant treatment of BNET is highly variable (10). Adjuvant chemotherapy may be recommended to patients with a Ki67 index of more than $10 \%$. Hormonal treatment appears to be feasible in patients who exhibit a positive expression of hormon receptor. ${ }^{10}$ Chemoregimens used to treat the usual type ductal breast carcinoma are also utilized in similar setting in BNET. On the other hand, in primary small cell chemoregimens similar to those used for lung neuroendocrine carcinoma have been attempted in the primary breast NEC.

Herein, we have reported two diferrent histological subtype of BNET. Cases were detected at an early stage. Surgery was performed to them. As in first case, breast-conserving surgery is the choice of treatment. They received adjuvant treatment. Small cell type was treated like lung NEC with sisplatin-etoposide. In second case, solid NET patient had co-morbid diseases. She was treated by hormonotherapy. 
Primary BNET is a rare tumor. Their long term prognosis and biologic behavour is not well known. The treatment plan should be based on the characteristics of the tumor and patient.

\section{REFERENCES}

1. Tavassoli FA, Devilee P. Tumours of the breast. In: Tavassoli FA, Devilee P, editors. Pathology and genetics of tumours of the breast and female genital organs. World Health Organization Classification of Tumours Series. Lyon: IARC Press; 2003: 32-34.

2. Cubilla AL, Woodruff JM. Primary carcinoid tumor of the breast: a report of eight patients. Am J Surg Pathol 1: 283292, 1977.

3. Tajima S, Horiuchi $\mathrm{H}$. Neuroendocrine tumor, well differentiated, of the breast: a relatively high-grade case in the histological subtype. Case Rep Pathol 2013;2013:204065.

4. Brask JB, Talman MM, Wielanga VT. Neuroendocrine carcinoma of the breast- a pilot study of a Danish population of 240 breast cancer patients. APMIS 122: 585-592, 2014.

5. Adegbola T, Connolly CE, Mortimer G. Small cell neuroendocrine carcinoma of the breast: a report of three cases and review of the literature. J Clin Pathol 58: 775-778, 2005.

6. Ouzreiah Nawawi, Keat Ying Goh, Kartini Rahmat.A Rare Case of Primary Infiltrating Neuroendocrine Carcinoma of the Breast. Iran J Radiol 9: 212-216, 2012.

7. Tian Z, Wei B, Tang F et al. Prognostic significance of tumor grading and staging in mammary carcinomas with neuroendocrine differentiation. Hum Pathol 42: 1169-1177, 2011.

8. Sapino A, Papotti M, Righi L. Clinical significance of neuroendocrine carcinoma of the breast. Ann Oncol 12: 115-117, 2001.

9. Francesca R, Matteo L, Stefano La R et al. Neuroendocrine breast cancer: retrospective analysis of 96 patients and review of literature. Int J Surg 11(S1), S79-S83, 2013.

10. Yildirim $Y$, Elagoz S, Koyuncu A et al. Management of neuroendocrine carcinomas of the breast: A rare entity. Oncol Lett 2: 887-890, 2011.

\section{Correspondence}

Dr. Havva Yesil CINKIR

Dr. A.Y. Ankara Onkoloji Eğitim ve Araştırma Hastanesi

Tibbi Onkoloji Bölümü

Demetevler, ANKARA / TURKEY

Tel: (+90.312) 3360909

Fax: (+90.312) 3340352

e-mail: doctoryesil82@yahoo.com 